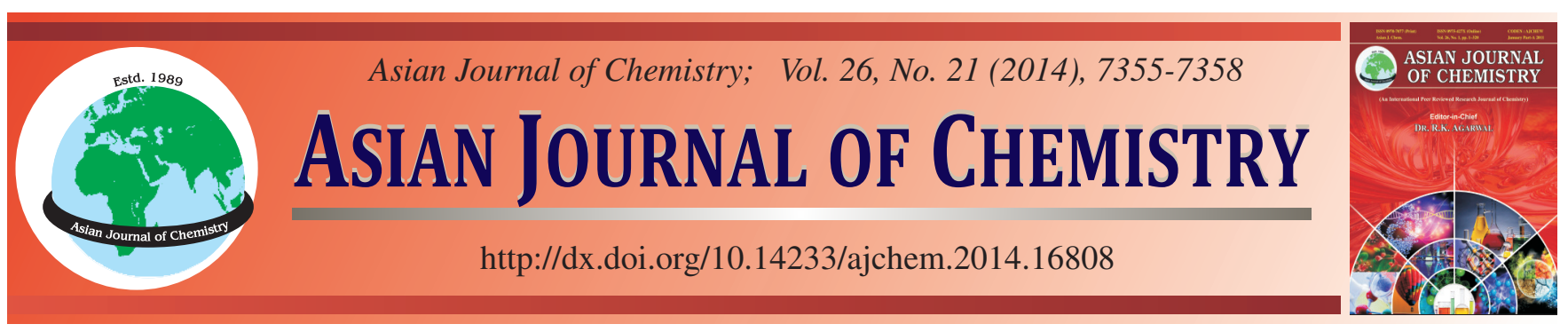

\title{
Design, Synthesis and Crystal Structure Analysis of Co(II) and Cd(II) Coordination Compounds with Benzimidazole Derivative Ligands
}

\author{
DAN Sun ${ }^{1}$, Ke-Qi PAN ${ }^{2}$ and HaI-Jun Xu ${ }^{1, *}$
}

${ }^{1}$ Jiangsu Key Lab of Biomass-Based Green Fuels and Chemicals, College of Chemical Engineering, Nanjing Forestry University, Nanjing 210037, P.R. China

${ }^{2}$ College of Chemistry and Chemical Engineering, Southeast University, Nanjing 211189, P.R. China

*Corresponding author: Fax:+86 25 85418873; Tel: +86 25 85427432; E-mail: xuhaijun@njfu.edu.cn

Received: 3 December 2013;

Accepted: 12 March 2014;

Published online: 30 September 2014;

AJC-16136

Two benzimidazole complexes of $\mathrm{Cd}(\mathrm{II})$ and $\mathrm{Co}(\mathrm{II})(\mathbf{1}$ and $\mathbf{2})$ were synthesized and characterized by single-crystal X-ray diffraction. The structure analysis indicates that the $\mathrm{Cd}(\mathrm{II})$ complex belongs to tetragonal $\mathrm{P} 4{ }_{1}{ }_{2}{ }_{2} 2$ space group with $\mathrm{a}=0.85006(17) \mathrm{nm}, \mathrm{b}=0.85006$ (17) $\mathrm{nm}, \mathrm{c}=2.9594(6) \mathrm{nm}, \mathrm{V}=2.1385(7) \mathrm{nm}^{3}, \mathrm{Z}=4$. Each Cd(II) atom coordinates with two benzimidazole derivative ligands and two nitrate anions in the shape of coordination polyhedron existing between the dodecahedron and tetragonal antiprism. In the crystal structure, the adjacent coordination units were connected together through strong intermolecular $\mathrm{N}-\mathrm{H} \cdots \mathrm{O} \mathrm{H}$-bonding interactions, which result in the formation of a two-dimension supramolecular structure. For the $\mathrm{Co}(\mathrm{II})$ complex with chiral ligand, the same handedness structure was formed and crystallized in the orthorhombic P $22_{1} 2_{1}{ }_{1}$ space group with a $=0.80052(6) \mathrm{nm}, \mathrm{b}=1.39487(8) \mathrm{nm}, \mathrm{c}=1.529340(10) \mathrm{nm}, \mathrm{V}$ $=1.70769(16) \mathrm{nm}^{3}, \mathrm{Z}=4$. Each $\mathrm{Co}(\mathrm{II})$ atom coordinates with one benzimidazole derivative ligand and two chlorides in distorted tetrahedron geometry.

Keywords: Crystal structure, Benzimidazole, Chiral coordination, Cd(II), Co(II).

ᄂ - - - - - - - - - - - - - - - - - - - - - - - - - - - - - - -

\section{INTRODUCTION}

The design and synthesis of organic-inorganic complexes have attracted much attention in coordination chemistry not only for intriguing structural motifs, but also for their promising applications in multidisciplinary areas, such as catalysis, molecular adsorption, optics, magnetism, molecular recognition, etc. ${ }^{1-7}$. Sometimes, such hybrid structures were considered as the primary structures, which can be further organized to supramolecular structures by coordination or/and hydrogen bonds or other weaker supramolecular interactions, such as strong $\mathrm{N}-\mathrm{H} \cdots \mathrm{O}$ intermolecular H-bonding interactions ${ }^{8-10}$. For such kinds of complexes, it is important to rationally design and select the organic building blocks and metal centers with suitable coordination geometry in the self-assembly process ${ }^{11-13}$. However, the structure of coordination polymers is influenced by the conformation of organic ligands and their substitute group, reactants and molar ratio, etc., which makes the controllable preparation to be a great challenge ${ }^{14-17}$. Benzimidazole with flexible substitute groups are good $\mathrm{N}$-coordination sites donors in structure chemistry, their flexible substitute groups allows the ligands to bend when it coordinates to metal ion centers, which will cause the structural diversity and may result in novel aim structures. In recent years many coordination complexes with interesting structures constructed from flexible imidazole ligands have been successfully synthesized ${ }^{18-20}$, while chiral coordination complexes with such organic linkers are still remain less documented ${ }^{21}$. As the continuing work, we present here two transition-metal (Co(II) and $\mathrm{Cd}(\mathrm{II})$ ) complexes based on flexible benzimidazole ligands ((R/S)-HBME $=(\mathrm{R} / \mathrm{S})-1-(1 H$-benzimidazol-2-yl) ethanol and (S)-HDBME $=(\mathrm{S})-1,2-b i s(1 H$-benzimidazol-2-yl)ethanol) with chiral substitute groups. The two compounds were characterized by single crystal structures and spectroscopic techniques.

\begin{tabular}{l} 
EXPERIMENTAL \\
\hline NMR spectra were recorded in $\mathrm{CDCl}_{3}$ solution on a Bruker \\
AV 300 spectrometer at $300 \mathrm{MHz}$ for ${ }^{1} \mathrm{H}$. The chemical shifts \\
were expressed in ppm $(\boldsymbol{\delta}$ scale) relative to the reference com- \\
pound tetramethylsilane (TMS). The synthesis of complex 1, \\
(S)-HDBME and complex 2 were shown in Schemes I and \\
III, respectively. \\
Synthesis: The reagents and solvents employed were \\
commercially available and used as received without further \\
purified. Ligand (R/S)-1-(1H-benzimidazol-2-yl) ethanol ((R/ \\
S)-HBME) was synthesized according to the literature ${ }^{22}$.
\end{tabular}


Synthesis of $\mathrm{Cd}[(\mathrm{R} / \mathrm{S})-\mathrm{HBME}]_{2}\left(\mathrm{NO}_{3}\right)_{2}$ (complex 1): Complex 1 was prepared as shown in Scheme-I. In a thickwalled pyrex tube, a mixture of (R/S)-HBME (0.0162 g, 0.1 $\mathrm{mmol}), \mathrm{Cd}\left(\mathrm{NO}_{3}\right)_{2} \cdot 4 \mathrm{H}_{2} \mathrm{O}(0.0154 \mathrm{~g}, 0.050 \mathrm{mmol})$ and 15 drops of anhydrous ethanol were frozen and sealed under vacuum, then placed inside an oven at $100{ }^{\circ} \mathrm{C}$. The brown block-like crystals were obtained after $48 \mathrm{~h}$ of heating.

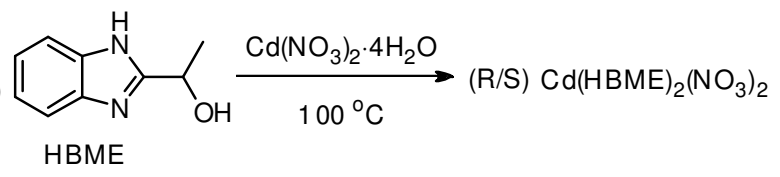

Scheme-I

Synthesis of ligands (S)-1,2-bis(1H-benzimidazol-2yl)ethanol ((S)-HDBME): (S)-HDBME was prepared as shown in Scheme-II. Benzene-1, 2-diamine (1.19 g, $11 \mathrm{mmol})$ was dissolved in hydrochloric acid $(12 \mathrm{~mL}, 4 \mathrm{M})$ at $100{ }^{\circ} \mathrm{C}$ and (S)-hydroxysuccinic acid ( $5 \mathrm{mmoL}, 0.67 \mathrm{~g}$ ) was added to the solution. The mixture were then heated to reflux for $7 \mathrm{~h}$ at 115 ${ }^{\circ} \mathrm{C}$. After cooling to room temperature, the product was divided by neutralizing the mixture solution using dilute $\mathrm{NaOH}$ solution to make the $\mathrm{pH}$ 8-9. Light yellow solid product was obtained by filtration, being washed with distilled water and ethanol. The yield: $1.14 \mathrm{~g}(82 \%)$ on the basis of (S)-(-)hydroxysuccinic acid. ${ }^{1} \mathrm{H} \mathrm{NMR}\left(\mathrm{CDCl}_{3}, 300 \mathrm{MHz}\right): \delta 3.29$ (m, $1 \mathrm{H}), \delta 3.58$ (m, $1 \mathrm{H}), 5.38$ (m, $1 \mathrm{H}), 6.22$ (b, $2 \mathrm{H}), 7.15$ (m, $4 \mathrm{H}), 7.49(\mathrm{~m}, 4 \mathrm{H})$.

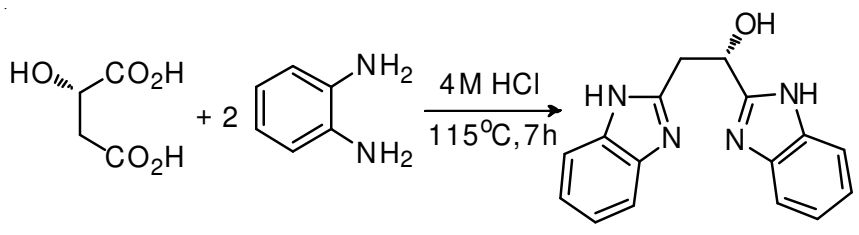

Scheme-II

Synthesis of $\mathrm{Co}(\mathrm{S})-\mathrm{H}_{2} \operatorname{dibzim}(\mathrm{s})-\mathrm{HDBMECl}_{2}$ (complex 2): Complex 2 was prepared as shown in Scheme-III. In a thick-walled Pyrex tube, a mixture of (S)-(-)1,2-bis(1Hbenzimidazol-2-yl)ethanol (0.0278 g, $0.1 \mathrm{mmol}), \mathrm{CoCl}_{2} \cdot 6 \mathrm{H}_{2} \mathrm{O}$ $(0.0119 \mathrm{~g}, 0.05 \mathrm{mmol})$ and 15 drops of anhydrous ethanol were frozen and sealed under vacuum, then placed inside an oven at $125^{\circ} \mathrm{C}$. The blue block-like crystals were obtained after $24 \mathrm{~h}$ of heating.

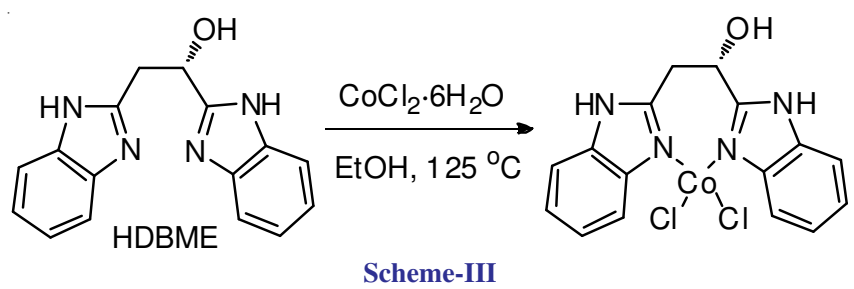

Crystal structure determination: Crystallographic data of 1-2 were collected at $292 \mathrm{~K}$ on a Bruker SMART APEX CCD diffractometer with graphite-monochromatized $\mathrm{MoK}_{\alpha}$ radiation $(\lambda=0.071073 \mathrm{~nm})$. An empirical absorption correction was applied. The structures were solved by the direct method and refined using the SHELXL-97 software ${ }^{23}$. All nonhydrogen atoms were refined by full-matrix least-squares method on $\mathrm{F}^{2}$ with anisotropy thermal parameters, while all hydrogen atoms were refined in calculated positions, assigned isotropic thermal parameters and allowed to ride their parent atoms. Crystallographic data and structure refinement results are summarized in Table- 1 .

TABLE-1

CRYSTALLOGRAPHIC DATA AND STRUCTURE REFINEMENT RESULTS FOR Cd(II) AND Co(II) COMPLEXES

\begin{tabular}{|c|c|c|}
\hline Compound & 1 & 2 \\
\hline Empirical formula & $\mathrm{C}_{18} \mathrm{H}_{20} \mathrm{~N}_{6} \mathrm{O}_{8} \mathrm{Cd}$ & $\mathrm{C}_{16} \mathrm{H}_{14} \mathrm{~N}_{4} \mathrm{OCoCl}_{2}$ \\
\hline Formular weight & 560.81 & 408.14 \\
\hline Temperature (K) & 293(2) & 293(2) \\
\hline Wavelength $(\AA)$ & 0.71073 & 0.71073 \\
\hline Crystal system & Tetragonal & Orthorhombic \\
\hline Space group & $\mathrm{P} 4{ }_{1} 2{ }_{1} 2$ & $\mathrm{P} 2_{1} 2_{1} 2_{1}$ \\
\hline \multicolumn{3}{|l|}{ Unit cell dimension } \\
\hline $\mathrm{a}(\AA)$ & $8.5006(17)$ & $8.0052(6)$ \\
\hline $\mathrm{b}(\AA)$ & $8.5006(17)$ & $13.9487(8)$ \\
\hline c $(\AA)$ & $29.594(6)$ & $15.29340(10)$ \\
\hline$\beta\left({ }^{\circ}\right)$ & 90 & 90 \\
\hline Volume $\left(\AA^{3}\right)$ & $2138.5(7)$ & $1707.69(16)$ \\
\hline $\mathrm{z}$ & 4 & 4 \\
\hline$\rho($ calc $)\left(\mathrm{g} / \mathrm{cm}^{3}\right)$ & 1.742 & 1.587 \\
\hline Absorption coefficient & 1.081 & 1.328 \\
\hline $\mathrm{F}(000)$ & 1128 & 828 \\
\hline Crystal size (mm) & $0.10 \times 0.15 \times 0.20$ & $0.25 \times 0.20 \times 0.16$ \\
\hline \multirow[t]{3}{*}{ Limiting indices } & $-11<=h<=11$ & $-9<=\mathrm{h}<=9$ \\
\hline & $-11<=k<=11$ & $-16<=k<=16$ \\
\hline & $-38<=1<=38$ & $-18<=1<=18$ \\
\hline $\begin{array}{l}\text { Reflections collected/ } \\
\text { unique }\end{array}$ & $\begin{array}{l}18107 / 2533\left[R_{\text {(int) }}=\right. \\
0.0429]\end{array}$ & $\begin{array}{l}14349 / 3020\left[R_{(\text {int) }}=\right. \\
0.1023]\end{array}$ \\
\hline $\begin{array}{l}\text { Max. and Min. } \\
\text { transmission }\end{array}$ & 0.7230 and 0.6840 & 0.8156 and 0.7325 \\
\hline Refinement method & $\begin{array}{l}\text { Full-matrix least- } \\
\text { squares on } \mathrm{F}^{2}\end{array}$ & $\begin{array}{l}\text { Full-matrix least- } \\
\text { squares on } \mathrm{F}^{2}\end{array}$ \\
\hline Data/restraints/parameters & $2533 / 12 / 157$ & $3020 / 0 / 211$ \\
\hline Goodness-of-fit on $\mathrm{F}^{2}$ & 1.161 & 1.080 \\
\hline Final $R$ indices $[\mathrm{I}>2 \sigma(\mathrm{I})]$ & $\begin{array}{l}\mathrm{R} 1=0.0384 \\
\mathrm{wR} 2=0.1324\end{array}$ & $\begin{array}{l}\mathrm{R} 1=0.0763 \\
\mathrm{wR} 2=0.1656\end{array}$ \\
\hline $\mathrm{R}$ indices (all data) & $\begin{array}{l}\mathrm{R} 1=0.0476 \\
w R 2=0.1596\end{array}$ & $\begin{array}{l}\mathrm{R} 1=0.1055 \\
\mathrm{wR} 2=0.1831\end{array}$ \\
\hline $\begin{array}{l}\text { Absolute structure } \\
\text { parameter }\end{array}$ & $0.02(6)$ & $0.05(5)$ \\
\hline
\end{tabular}

\section{RESULTS AND DISCUSSION}

The cadmium complex 1 crystallizes in the tetragonal system (space group $\mathrm{P} 4{ }_{1}{ }_{1} 2$ ) (Fig. 1).

Two molecules of (R/S)-HBME and two nitrate ions are bounded directly to the metal ions, as bidenate ligands, give a $\mathrm{CdN}_{2} \mathrm{O}_{6}$ chromophore which is similar to the reported results ${ }^{20,24}$. Thus, $\mathrm{Cd}$ atom is eight-coorinated with two pyridinic like $\mathrm{N}$-atoms of the benzimidazole rings [N1 and N1A] and six oxygen atoms, two from hydroxyethyl groups oxygen atoms $[\mathrm{O} 1$ and $\mathrm{O} 1 \mathrm{~A}]$ and four from the nitrate ions oxygen atoms [O2, O4, O2A and O4A]. The nitro groups have the same coordination modes as exhibited in the reported result ${ }^{20,24}$, but two nitrate anions are quite disordered with the $\mathrm{O} 2(\mathrm{O} 4)$ and $\mathrm{O} 2$ '(O4') atom, with the occupancy factors of 0.31186 and 0.68814 , respectively. Selected bond distances and angle valences are given in Table-2. Cadmium-nitrogen bond distances are 2.218 (4) $\AA$ and relatively short with comparison with the literature ${ }^{20,24}$. However, cadmium-oxygen distances are 2.310 (4)-2.640 (2) $\AA$ and almost in agreement with those found in 


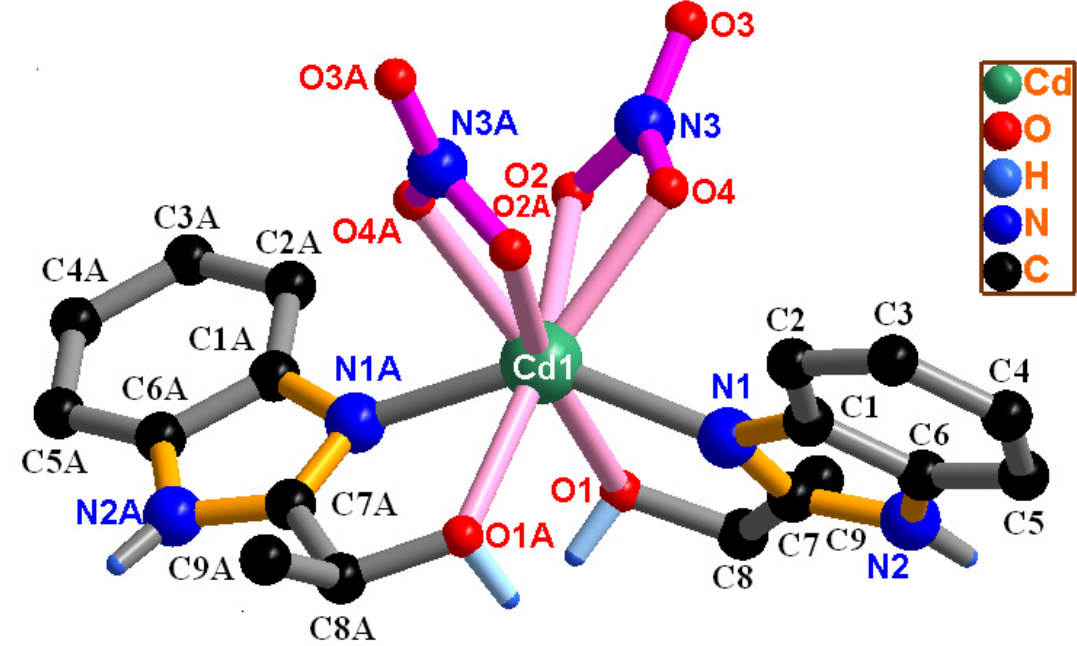

a

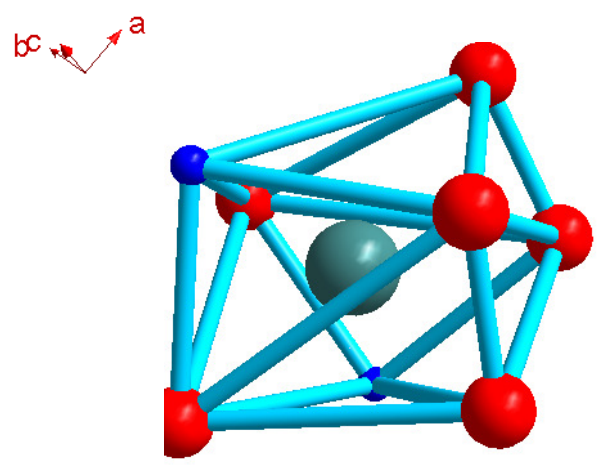

b

Fig. 1. A view with the atomic numbering scheme (a) and coordination polyhedron (b) of the complex 1. Hydrogen atoms have been omitted for clarity. Symmetry code: $1-\mathrm{y}, 1-\mathrm{x}, 0.5-\mathrm{z}$

the literature ${ }^{20,24}$. The cadimium complex is the shape of coordination polyhedron existing between the dodecahedron and tetragonal antiprism and similar to the reported geometrical structure $\mathrm{e}^{20,24}$. The fused benzene and imidazole rings are nearly planar with the largest deviations from the mean plane being 0.0257 (0.0048) $\AA$ at C5. The fused ring [C1, C2, C3, C4, C5, $\mathrm{C} 6, \mathrm{~N} 2, \mathrm{C} 7, \mathrm{~N} 1]$ makes an angle of $4.22(0.15)^{\circ}$ with respect to the plane $[\mathrm{C} 7, \mathrm{C} 8, \mathrm{O} 1, \mathrm{Cd} 1, \mathrm{~N} 1]$ and they are also approximately coplanar. The $\mathrm{C}-\mathrm{C}$ and $\mathrm{C}-\mathrm{N}$ bond lengths within the aromatic rings are normal [C-C distances range from 1.362 (10) to $1.409(8) \AA ; \mathrm{C}-\mathrm{N}$ distances range from 1.308 (7) to 1.415 (6) $\AA$ ] (Table-2). These bond lengths are similar to those observed for other benzimidazole derivatives ${ }^{18,20,24}$.

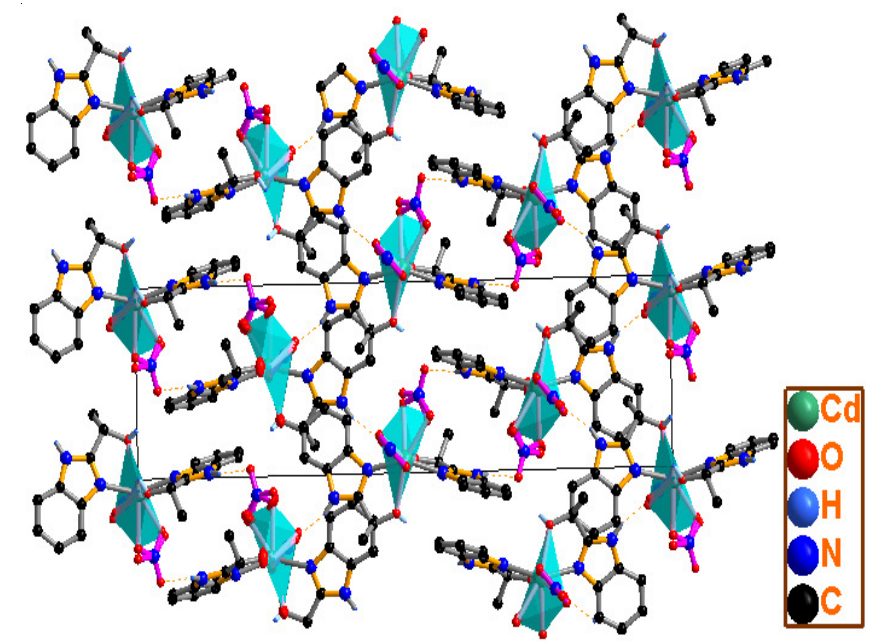

Fig. 2. A view of the 2-D hydrogen-bond network of $\mathbf{1}$ with metal atoms represented as polyhedra

\begin{tabular}{|c|c|c|c|c|}
\hline \multicolumn{5}{|c|}{$\begin{array}{c}\text { TABLE-3 } \\
\text { HYDROGEN-BOND GEOMETRY }\left(\AA{ }^{\circ}\right)\end{array}$} \\
\hline D-H $\cdots A$ & D-H $(\AA)$ & $\mathrm{H} \cdots \mathrm{A}(\AA)$ & $\mathrm{D} \cdots \mathrm{A}(\AA)$ & $\angle \mathrm{DHA}\left({ }^{\circ}\right)$ \\
\hline $\mathrm{N} 2-\mathrm{H} 2 \mathrm{~A} \cdots \mathrm{O}^{\mathrm{i}}$ & 0.86 & 2.1 & $2.926(6)$ & 158.9 \\
\hline $\mathrm{N} 2-\mathrm{H} 2 \mathrm{~A} \cdots \mathrm{O} 4^{\text {rii }}$ & 0.86 & 2.57 & $3.19(2)$ & 130.2 \\
\hline
\end{tabular}

Symmetry codes: (i) $-\mathrm{x}+3 / 2, \mathrm{y}+1 / 2,-\mathrm{z}+1 / 4$; (ii) $-\mathrm{x}+3 / 2, \mathrm{y}+1 / 2,-\mathrm{z}+1 / 4$

In the crystal structure, intermolecular $\mathrm{N}-\mathrm{H} \cdots \mathrm{O}$ interactions link the molecules into a two-dimensional network (Table-3, Fig. 2), in which they may be effective in the stabilization of the crystal packing. In the crystal structure, there are no evidence that was observed for the existence of intermolecular aromatic $\pi-\pi$ stacking interactions in the complex.

Molecular structure of the complex 2: The cobalt complex 2 crystallizes in the orthorhombic system (space group $\mathrm{P} 22_{1} 2_{1} 2_{1}$ ). The molecular structure of four-coordinated $\mathbf{2}$ consists of distorted tetrahedron geometry in which the cobalt atom is surrounded by two chlorides and one benzimidazole ligand [(S)-HDBME] (Fig. 3). In this structure, the cobalt was coordinated with $s p^{2} \mathrm{~N} 1$ and N3 instead of $s p^{3} \mathrm{~N} 2$ and N4 in the benzimidazole ring. Selected bond distances and angle valences are given in Table-4. The Co-N1 and Co-N3 bond length are 2.006 (6) and 1.993 (7) $\AA$, respectively, which is similar to the $\mathrm{Co}-\mathrm{N}_{\text {benzimidazole }}$ length in the literature ${ }^{25,26}$. Compared to the angle of ideal tetrahedron is $109.28^{\circ}$, while the N-Co-N and N-Co-Cl angle range from 105.3 (3) to 114.0 $(2)^{\circ}$ and the coordination environment around Co center significantly deviates from an idea tetrahedron which can be best described as severely distorted tetrahedron. In addition, the plane formed by atoms Cl1-Co1-Cl2 makes an angle of 86.89 $(0.21)^{\circ}$ with respect to the plane formed by atoms N1-Co-N3

\begin{tabular}{clllllll}
\multicolumn{8}{c}{ TABLE-2 } \\
\multicolumn{10}{c}{ SELECTED BOND LENGTHS $(\AA)$ AND BOND ANGLES $\left({ }^{\circ}\right)$ FOR THE Cd(II) COMPLEX } \\
\hline Bond & Distance $(\AA)$ & Bond & Distance $(\AA)$ & \multicolumn{1}{c}{ Angle } & \multicolumn{1}{c}{$\left.{ }^{\circ}\right)$} & \multicolumn{1}{c}{ Angle } & $\left({ }^{\circ}\right)$ \\
\hline Cd1-N1 & $2.218(4)$ & Cd1-O2A & $2.51(2)$ & O1-Cd1-O1A & $94.3(3)$ & O4-Cd1-O4A & $75(4)$ \\
Cd1-O4 & $2.31(4)$ & O1-C8 & $1.397(7)$ & N1-Cd1-N1A & $141.0(3)$ & N $(1)-C d(1)-O(1)$ & $67.23(15)$ \\
Cd1-O1 & $2.427(5)$ & N1-C7 & $1.308(7)$ & N1-Cd1-O4 & $76.7(17)$ & O(4)-Cd(1)-O(1) & $103(2)$ \\
Cd1-O4A & $2.64(2)$ & N2-C7 & $1.352(6)$ & N1A-Cd1-O4 & $139.4(12)$ & O4A-Cd1-O1 & $148.3(7)$ \\
\hline
\end{tabular}


and they are also not completely perpendicular. The two fused benzene and imidazole rings are nearly planar with the largest deviations from the mean plane being $0.0325(0.0104) \AA$ at C5 and 0.0524 (0.0079) $\AA$ at C10. These two fused ring make a dihedral angle of $16.20(0.16)^{\circ}$. In addition, there are also three weak intermolecular $\mathrm{N}-\mathrm{H} \cdots \mathrm{Cl}$ and one $\mathrm{O}-\mathrm{H} \cdots \mathrm{Cl}$ hydrogen bond (Table-5 and Fig. 4) between the carbonyl and hydroxy groups which link the molecules into a one-dimesional network, in which they may be effective in the stabilization of the structure.

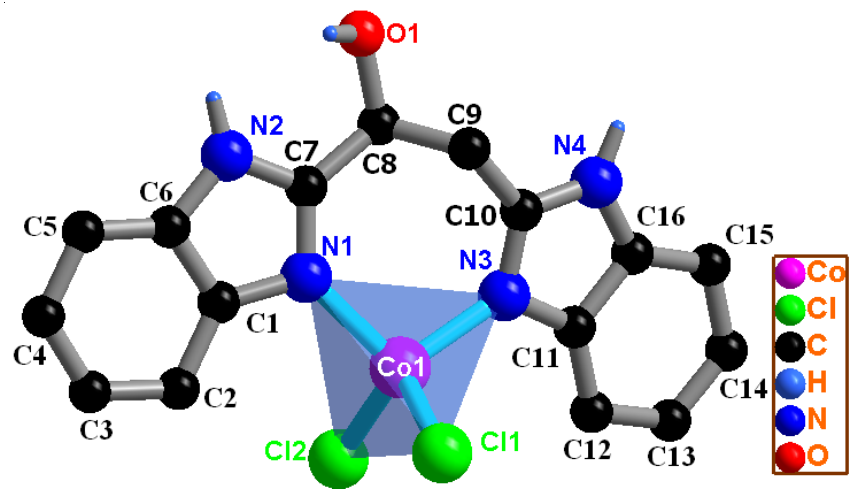

Fig. 3. View of the coordination environment of $\mathrm{Co}(\mathrm{II})$ and (S)-HDBME in complex 2. Hydrogen atoms have been omitted for clarity

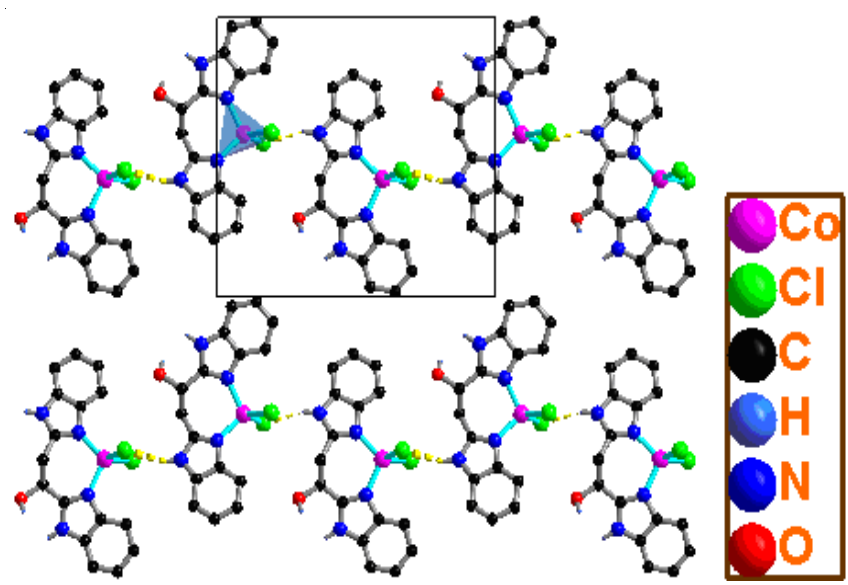

Fig. 4. Molecular one-dimensional chain hydrogen-bond structure of complex 2 viewed along the a-direction

\begin{tabular}{cccccc}
\multicolumn{7}{c}{ TABLE-4 } \\
\multicolumn{7}{c}{ SELECTED BOND LENGTHS $(\AA)$ AND } \\
BOND ANGLES $\left(^{\circ}\right)$ FOR Co(II) COMPLEX \\
\hline Bond & Dist. $(\AA)$ & Bond & Dist. $(\AA)$ & Bond & Dist. $(\AA)$ \\
\hline Co1-N3 & $1.993(7)$ & C8-O1 & $1.425(12)$ & Co1-Cl2 & $2.265(2)$ \\
Co1-N1 & $2.006(6)$ & C10-N3 & $1.308(9)$ & C7-N1 & $1.339(9)$ \\
Co1-Cl1 & $2.238(3)$ & C10-N4 & $1.369(11)$ & C7-N2 & $1.348(11)$ \\
\hline \multicolumn{1}{c}{ Angle } & $\left({ }^{\circ}\right)$ & Angle & $\left(^{\circ}\right)$ & Angle & $\left({ }^{\circ}\right)$ \\
\hline N3-Co1-Cl2 & $114.0(2)$ & N1-Co1-Cl2 & $107.3(2)$ & Cl1-Co1-Cl2 & $107.84(10)$ \\
N1-Co1-Cl1 & $112.1(2)$ & N3-Co1-N1 & $105.3(3)$ & C9-C8-C7 & $116.0(10)$ \\
O1-C8-C7 & $111.7(9)$ & N3-Co1-Cl1 & $110.3(2)$ & O1-C8-C9 & $109.5(9)$ \\
\hline
\end{tabular}

\section{Conclusion}

Two complexes of $\mathrm{Cd}(\mathrm{II})$ and $\mathrm{Co}(\mathrm{II})$ (1 and $\mathbf{2}$, respectively) were successfully synthesized and characterized by singlecrystal X-ray diffraction. The compounds crystallized in the space group of $\mathrm{P} 4{ }_{1} 2_{1} 2$ and $\mathrm{P} 2{ }_{1} 2_{1} 2_{1}$, respectively. There are also

\begin{tabular}{|c|c|c|c|c|}
\hline \multicolumn{5}{|c|}{$\begin{array}{c}\text { TABLE-5 } \\
\text { HYDROGEN-BOND GEOMETRY }\left(\AA{ }^{\circ},{ }^{\circ}\right)\end{array}$} \\
\hline D-H"A & D-H $(\AA)$ & $\mathrm{H} \cdots \mathrm{A}(\AA)$ & $\mathrm{D} \cdots \mathrm{A}(\AA)$ & $\angle \mathrm{DHA}\left(^{\circ}\right)$ \\
\hline N4-H4B $\cdots C l 1^{i}$ & 0.86 & 2.52 & $3.281(8)$ & 147.9 \\
\hline $\mathrm{N} 2-\mathrm{H} 2 \mathrm{C} \cdots \mathrm{Cl} 2^{\mathrm{ii}}$ & 0.86 & 2.71 & $3.299(9)$ & 126.7 \\
\hline $\mathrm{N} 2-\mathrm{H} 2 \mathrm{C} \cdots \mathrm{Cl} 1^{\text {iii }}$ & 0.86 & 2.74 & $3.276(10)$ & 121.7 \\
\hline $\mathrm{O} 1-\mathrm{H} 1 \mathrm{~A} \cdots \mathrm{Cl} 2^{\mathrm{ii}}$ & 0.82 & 2.70 & $3.507(13)$ & 170.1 \\
\hline
\end{tabular}

a strong intermolecular $H$-bonding interactions which are effective in the stabilization of the structure in $\mathbf{1}$ and $\mathbf{2}$.

\section{ACKNOWLEDGEMENTS}

The authors gratefully acknowledge the financial support received from the Committee of National Natural Science foundation of china (grant No. 21301092) and project funded by the Priority Academic Program Development of Jiangsu Higher Education Institutions (PAPD).

\section{REFERENCES}

1. B.L. Chen, N.W. Ockwig, A.R. Millward, D.S. Contreras and O.M. Yaghi, Angew. Chem. Int. Ed., 44, 4745 (2005).

2. M. Eddaoudi, D.B. Moler, H.L. Li, B.L. Chen, T.M. Reineke, M. O'Keeffe and O.M. Yaghi, Acc. Chem. Res., 34, 319 (2001).

3. M. Xue, S.Q. Ma, Z. Jin, R.M. Schaffino, G.S. Zhu, E.B. Lobkovsky, S.L. Qiu and B.L. Chen, Inorg. Chem., 47, 6825 (2008).

4. Z. Jin, H.Y. Zhao, X.J. Zhao, Q.R. Fang, J.R. Long and G.S. Zhu, Chem. Commun., 46, 8612 (2010).

5. L. Pan, T. Frydel, M.B. Sander, X. Huang and J. Li, Inorg. Chem., 40, 1271 (2001).

6. M.T. Caudle, J.W. Kampf, M.L. Kirk, P.G. Rasmussen and V.L. Pecoraro, J. Am. Chem. Soc., 119, 9297 (1997).

7. F.Y. Yi, W. Yang and Z.M. Sun, J. Mater. Chem., 22, 23201 (2012).

8. D.W. Fu, M.M. Zhao and J.Z. Ge, J. Mol. Struct., 1006, 227 (2011).

9. L. Zhao, X.T. Dong, Q. Cheng and J.X. Zhao, Asian J. Chem., 25, 4646 (2013).

10. H.J. Xu, L. Xu and Y.K. Zhang, Inorg. Chem. Commun., 28, 94 (2013).

11. Y.Q. Tian, C.X. Cai, Y. Ji, X.Z. You, S.M. Peng and G.H. Lee, Angew. Chem. Int. Ed., 41, 1384 (2002).

12. G.R. Desiraju, J. Am. Chem. Soc., 135, 9952 (2013).

13. D.W. Fu, W. Zhang and R.G. Xiong, Cryst. Growth Des., 8, 3461 (2008).

14. Y.Q. Tian, C.X. Cai, X.M. Ren, C.Y. Duan, Y. Xu, S. Gao and X.Z. You, Chem. Eur. J., 9, 5673 (2003).

15. J.K. Hu, X.Y. Yu, Y.H. Luo, X.-F. Wang, F.-X. Yue and H. Zhang, Inorg. Chem. Commun., 32, 37 (2013).

16. Y.L. Yao, Y.X. Che and J.M. Zheng, Inorg. Chem. Commun., 11, 883 (2008).

17. P.C. Song, W.C. Song, Y. Tao, T.L. Hu and Y.F. Zeng, Solid State Sci., 12, 1357 (2010).

18. H.J. Xu, Y.X. Liu, Z. Shen, Y.Q. Tian and X.Z. You, Z. Anorg. Allg. Chem., 631, 1349 (2005).

19. Y.Q. Tian, H.J. Xu, L.H. Weng, Z.X. Chen, D.Y. Zhao and X.Z. You, Eur. J. Inorg. Chem., 1813 (2004).

20. B. Barszcz, A. Jablonska-Wawrzycka, K. Stadnicka and J. Jezierska, Polyhedron, 27, 3500 (2008).

21. L. Han and M. Hong, Inorg. Chem. Commun., 8, 406 (2005).

22. R. Xia and H.J. Xu, Acta Crystallogr., E64, o1223 (2008).

23. G.M. Sheldrick, SHELXTL Version 5.10 (Bruker AXS Inc., Madsion), (1997).

24. J.M. Grevy, F. Tellez, S. Bernés, H. Nöth, R. Contreras and N. BarbaBehrens, Inorg. Chim. Acta, 339, 532 (2002).

25. W.-H. Sun, C. Shao, Y. Chen, H. Hu, R.A. Sheldon, H. Wang, X. Leng and X. Jin, Organometallics, 21, 4350 (2002).

26. N.H. Tarte, S.I. Woo, L. Cui, Y.-D. Gong and Y.H. Hwang, J. Organomet. Chem., 693, 729 (2008). 